\title{
Exploration of teaching mode aiming at engineering training
}

\section{Cunli Duan, Wangyun Liu, Yuhong Zhang}

Cunli Duan, Wangyun Liu, Yuhong Zhang, "Exploration of teaching mode aiming at engineering training," Proc. SPIE 10452, 14th Conference on Education and Training in Optics and Photonics: ETOP 2017, 104525E (16 August 2017); doi: 10.1117/12.2269744

SDIE Event: 14th Conference on Education and Training in Optics and Photonics, ETOP 2017, 2017, Hangzhou, China 


\title{
Exploration of teaching mode aiming at engineering training
}

\author{
Cunli Duan, Wangyun Liu, Yuhong Zhang
}

(School of Photoelectrical Engineering, Xi'an Technological University, Xi'an 710021, People's Republic of China)

Abstract: Specialty of optoelectronic information science and engineering is aim to cultivate senior specialized talents of photoelectric system design and implementation. The optical signal transmission is indispensable in the photovoltaic system. The problems existing in the teaching of information classes of the specialty at present are analysised and the teaching mode aiming to engineering training is proposed. The specific content is as follows: The principle problem of optical information transmission system is solved in the theoretical teaching in the classroom, the problem of the system design and simulation implementation is solved in the course design, the problem of the hardware implementation of the system is solved in the professional experiments. The training of the whole process from the principle of optical information transmission system design, software simulation to hardware implementation is achieved through this kind of teaching mode.

Keywords: Engineering training; Optical information transmission system; Teaching

Teaching research university is given priority to undergraduate course education, discipline construction,scientific research as the auxiliary, strengthen the ability of engineering practice, training institute and enterprise oriented a line of specialized technical personnel. To cooperate the teaching goal of colleges and universities, colleges and universities education workers for a variety of teaching mode of exploration: the research of professor yi-lin song of heilongjiang university "Research-based teaching model exploration based on the applied talents training"[1]; Dr Jian-yong zuo of Tongji university studied: " Practical teaching mode and case analysis for engineering" ${ }^{[2]}$ and so ${ }^{[3,4]}$; In the undergraduate teaching of institutions of higher learning, the immediate problem is to explore the teaching mode of cultivate and strengthen the engineering practice ability, the effective combination of theoretical knowledge and practical ability. In this paper, A set of teaching mode suitable for Information classes, aiming at training students' engineering practical ability will be explored in Optoelectronic Information Science and Engineering courses of undergraduate teaching as an example.

\section{The current status and the existing problems in Information classes of Optoelectronic Information Science and Engineering}

Optoelectronic information science and engineering is a new professional to adapt to photoelectric development combine Optoelectronic technology, Image analysis technology, Communication technology, Information fusion technology, Computer science, The control technology into an organic whole. The training goal is the engineering senior specialized talents have the basic theory, basic knowledge and basic skills of Optoelectronic information science and engineering, be able to engage in technology research and development, engineering design and production management in the field of Applied optics, Optoelectronics and related information science, especially in photoelectric information industry fields. Information classes of Optoelectronic Information Science and Engineering come from Electronic Information Engineering, The courses of Electronic Information Engineering is as Table 1. Professional Settings have a set of curriculum of professional foundation courses, professional courses and engineering training process in order to achieve the training objectives of this major. Photoelectric information class curriculum isn't the major research direction of learning of optoelectronic information science and engineering, the total class curriculum is too less, the curriculum as Table 2. It basically 
set up professional foundation courses and part of professional courses, and it has little practice teaching link. The teaching mode is the traditional teaching mode: Mainly classroom teaching. It mainly teaches the basic content of communication principle and the relevant theoretical knowledge of communication technology. The problems must be solved are as follows: What kind of teaching model is adopted and how to put them into these courses in the teaching within the limited class hour to let the students effectively master the photoelectric signal from the acquisition, loading, transport, accepting, restore the entire process to achieve the teaching effect of combining theoretical study with the engineering practice.

Table 1 The courses of Electronic Information Engineering

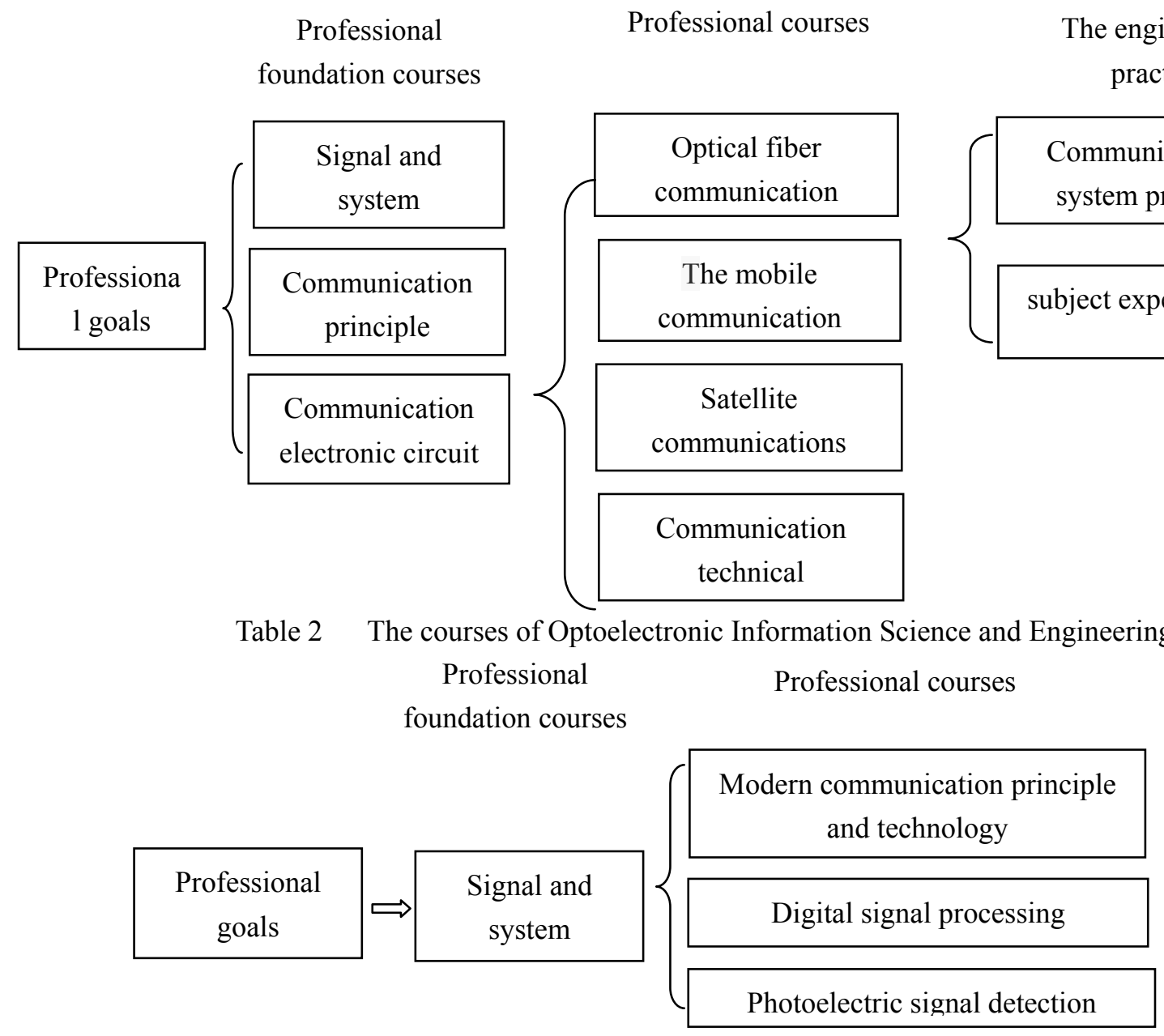

\section{The construction idea of the training platform}

For undergraduate teaching of information class curriculum of Optoelectronic Information Science and Engineering, The teaching mode aiming at training students' engineering practical ability. The construction idea is to cultivating the practical ability of students as the theme, to realizing the optical signal collection, transmission and receive training platform as the foundation, to training students to start with the information transmission system design of life. According to the requirements of the actual system need technology to study related theory knowledge in order to meet the actual needs of information transmission system design. Do theoretical study to serve the practice requirements to stimulate students' interest in learning. Let the students to 
design their own information transmission system design and simulation test using the MATLAB software simulation training platform of information system after information system design is completed. The aim is to train the students' computer programming ability, communication system simulation implementation capability and the simulation of different signal test ability. The hardware platform achieving information transmission system is made at the experimental practice link according to the result of software simulation to train students' information circuit implementation and hands-on ability. To achieve the target of raining students' engineering practical ability through the whole process training of the information transmission system design, simulation, experimental implementation.

\section{The construction of training platform}

The construction of practice training platform is on the basis of the development of the small communication system from the Voice, Image, Data Signal Acquisition, Coding, Modulation, the launch, Transmission, Accept, Demodulation, Decoding, to the final signal recovery. The overall plan diagram as shown in Table 3 mainly divided into part of classroom teaching, course design and professional experiment.

\section{Table 3 Training platform overall scheme}

Training content requirements

\begin{tabular}{|c|}
\hline \\
The signal's \\
Acquisition, \\
coding, \\
Modulation, \\
launch, \\
Transmission, \\
Accept, \\
demodulation, \\
Decoding, \\
signal recovery \\
\hline
\end{tabular}

The teaching task

On the basis of small information transmission system, the problem oriented

to complete the active learning ability in classroom teaching

Based on MATLAB to complete the professional software application ability training of the students through the curriculum design of the information transmission system simulation implementation

The training of the students' practical ability is completed by the professional experiment of hardware implementation of information transmission system
Concrete implementation method

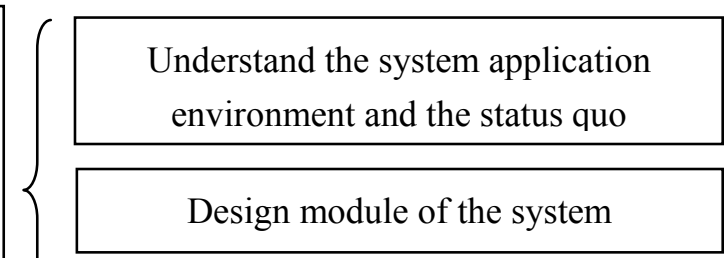

Design information transmission system

Using the software simulation design system module

Use of software simulation electronic circuit

Testing of The simulation system

Information transmission system hardware implementation and test 


\section{(1). Classroom teaching}

There are two purposes in undergraduate education of University: One is to provide the basis of systematic knowledge has been obtained from nature. The other is to effectively teach method to explore and test the knowledge in the past or the future ${ }^{[5]}$. The classroom teaching is the main link of undergraduate education, which is the main link for the students to learn the basic theoretical knowledge and to establish professional knowledge system. The traditional teaching mode is given priority to the teacher's teaching, the advantage is that students learn knowledge systematically, good teaching progress control, the disadvantage is that the students learning is passive, active participation enthusiasm is not enough, which leads to the effect of students' learning in general.

The teaching mode of the engineering practice as the goal is given priority to the students' learning in the classroom teaching, the teaching mode as shown in Table 4. The information class curriculum for the Photoelectric information engineering is on the basis of small information transmission system, the relevant problems of practical use is put forward according to environment of the system be used, let the student check information to solve the problems, so as to elicit the technical problems needed to be solved in information transmission system, then to solve these problems one by one. The students summarize the knowledge with a shorter time under teacher's guidance when the process is completed so as to complete the systematic design of the whole information transmission system: Begin from the characteristics of the signal, according to the signal transmission environment, the basic technology of sending and receiving module, to the specific implementation of the electronic circuit and so on. The students complete the overall scheme design of the information transmission system through such problem oriented type learning. The students' active learning ability and project design ability be cultivated and the students' ask question ability, problem-solving ability and the ability to comprehensive analysis problems also be exercised through such classroom teaching process.

Table 4 Problems oriented model of classroom teaching

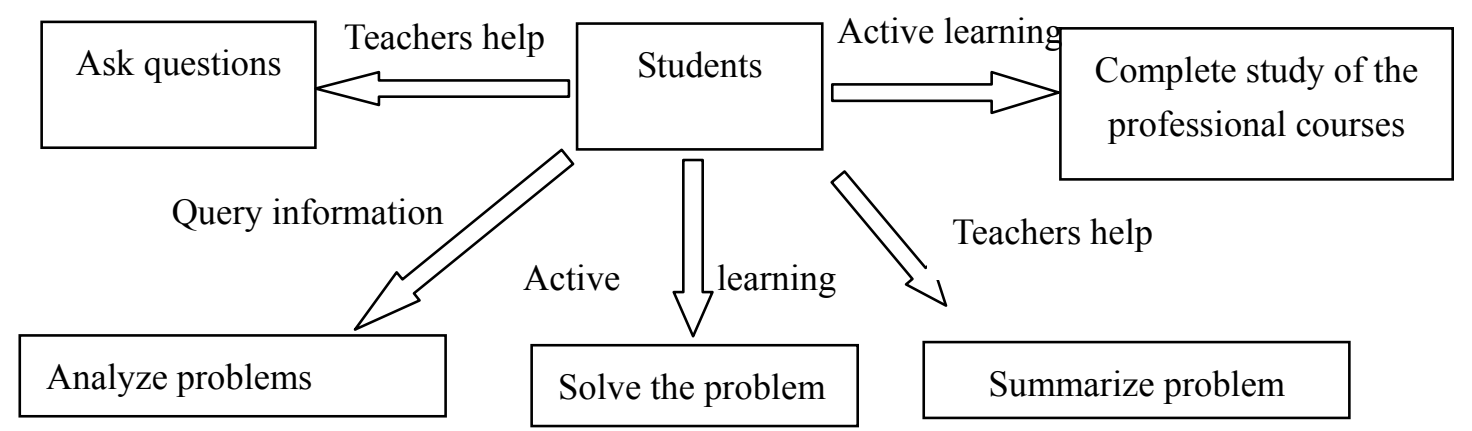

\section{(2). Curriculum design}

Curriculum design is primarily aimed at some practical stronger courses, according to different specialties, course time is usually one week to three weeks. With the rapid development of computer technology, it is becoming more and more popular for the curriculum design to simulate systematically the experiment using computer software. For example, PROTEUS software for electronic circuits, the ZEMAX software for the optical design, the MATLAB software for the communication principle and the digital signal processing, etc. It can build the complex system application environment to a model, modular the professional technical, make the design of the system without using complex, high cost of hardware implementation, complete the simulation and test of the design system, real-time and quickly adjust and modify the system design according to the result of test through the application of computing technology. 
The information transmission system the students design in the classroom teaching in the teaching model of engineering practice as the goal be simulation implemented using the MATLAB software or LABVIEW software, for different simulation signal testing, convenient and fast to adjust and modify the design of the system. Students practice through software simulation, training the students' computer programming skills, and professional software application ability.

\section{(3). Professional experiment}

Professional experiment is the main part in the engineering teaching of colleges and universities, it is a process for the students to implement the theoretical knowledge. In traditional experiments, it is the teacher who write a lab handouts (including test principle, experiment contents, experiment operation, experiment data processing, etc.) and tidy up the instruments, students only need to complete the experiment. Fewer students to think for why do so for the experiment, the experimental requirements for what purpose, what kinds of experimental phenomena is the ideal, what experiment data processing is reasonable, how to solve the problems in the experiment . Students learn swallowed and the practice learning effect is general.

In the teaching mode of engineering practice as the goal, the professional experiment content is the system of the students themselves design through a period of time to learn, and has been implemented by the computer simulation, and the testing is completed. The students' study enthusiasm in the experimental stage of hardware implementation is very high, and they are very familiar with the content. Students will have answers in the process of experiments and they can judge themselves the stand or fall of implementation phenomenon, so as to adjust at any time the experiment condition. The professional experiment is implemented by grouping, each student in one group responsible for part of the hardware implementation system, then the all modules are connect to complete the realization of the system, test and the analysis of the test results are completed finally. It is not only training the students' practical ability and the realization of the system capacity, also exercising the students' team cooperation ability through such experiment.

\section{Conclusion}

In the teaching mode of engineering practice as the goal, the information transmission system design and software simulation and hardware implementation process are complete by problem oriented type of classroom teaching, the computer application training of curriculum design, give priority to the hands-on practice ability of professional experiment, so as to achieve the training goal of the undergraduate education of teaching research university, to strengthen the ability of engineering practice, and to train institute and enterprise oriented a line of specialized technical personnel.

Acknowledgments: The research was supported by the xi'an technological university educational reform project (Grants NO.16JGY02)

\section{References:}

[1]. Song yilin, Gao shumei and Chen gang. Research-based teaching model exploration based on the applied talents training [J]. Heilongjiang Researches on Higher Education, 2014（6）: 142-144

[2]. Zuo jianyong. Engineering-oriented practice training teaching model and case study[J]. Research and Exploration in Laboratory, 2011(7): 157-161.

[3]. Wan min and Yang chao. The development of engineering practice teaching platform based on the CDIO mode [J]. Theory and Practice of Contemporary Education, 2014(10): 60-61. 
[4]. Li junqiu, Zhang qinghui, Lu danju, et al. Teaching model explore of electronic information engineering specialty integrated practical[J]. Education Teaching Forum, 2016(7): 117-119.

[5]. Bai suying. Undergraduate teaching model explore of research university[J]. Heilongjiang Researches on Higher Education, 2006(1): 125-126. 